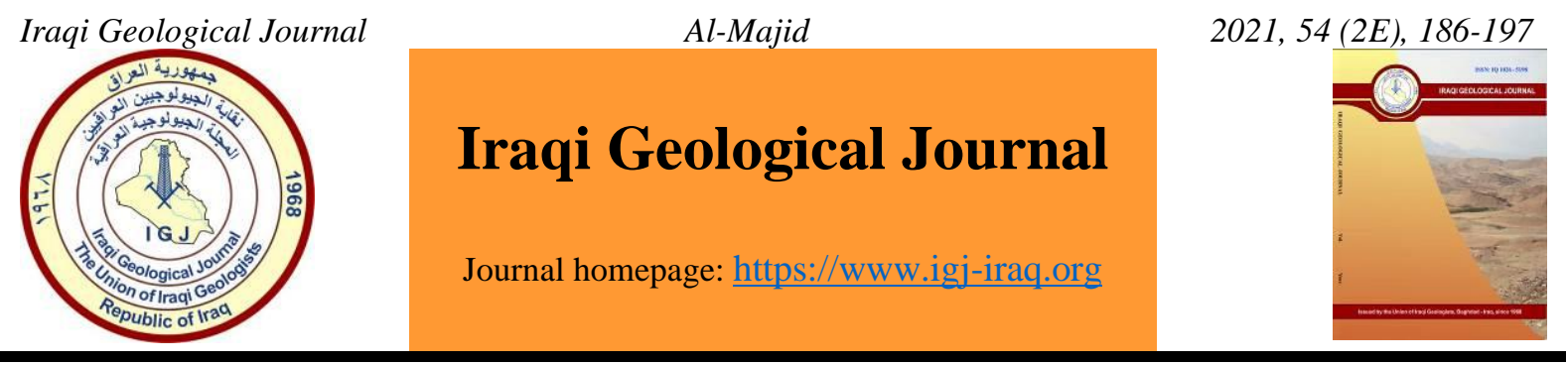

\title{
Petrophysical Properties Estimation of Euphrates Reservoir in Qayyarah Oil Field Using Core and Well Log Data
}

\author{
Maan H. Abdullah Al-Majid ${ }^{1, *}$ \\ 1 Department of Petroleum Reservoir Engineering, College of Petroleum and Mining Engineering, University of Mosul, \\ Mosul, Iraq \\ * Correspondence: maan.abdalla@uomosil.edu.iq
}

Received: 5 August 2021; Accepted: 30 August 2021; Published: 30 November 2021

\begin{abstract}
The Early Miocene Euphrates Formation is characterized by its oil importance in the Qayyarah oil field and its neighboring fields. This study relied on the core and log data analyses of two wells in the Qayyarah oil field. According to the cross-plot's information, the Euphrates Formation is mainly composed of dolomite with varying proportions of limestone and shale. Various measurements to calculate the porosity, permeability, and water saturation on the core samples were made at different depths in the two studied wells Qy-54 and Qy-55. A relationship between water saturation and capillary pressure has been plotted for some core samples to predict sites of normal compaction in the formation. The line regression for this relationship was considered as a function of the ratio of large voids to the total volume of voids in the sample. The coefficient of determination parameter was used in estimating the amount of homogeneity in the sizes of the voids, as it was observed to increase significantly at the sites of shale. After dividing the formation into several zones, the well log data were analyzed to predict the locations of oil presence in both wells. The significance of the negative secondary porosity in detecting the hydrocarbon sites in the Euphrates Formation was deduced by its correspondence with the large increase in the true resistivity values in both wells. More than $90 \%$ of the formation parts represent reservoir rocks in both wells, but only about 75\% of them are oil reservoirs in the well Qy-54 and nearly 50\% of them are oil reservoirs in the well Qy-55.
\end{abstract}

Keywords: Core data; Well log data; Water saturation; Capillary pressure; Qayyarah oil field

\section{Introduction}

The petrophysical properties are very important to understand the factors affecting the quality of the oil reservoir and the quantity of its production (Al-Baldawi, 2021). Well log is the main tool used to describe the petrophysical characteristics including lithology, porosity, water saturation, and permeability (Albeyati et al., 2021). Many researchers have been studied the petrophysical properties of carbonate rocks in several oil reservoirs in Iraq (Al-Majid, 2019; Al-Jawad and Kreem, 2016; Abdulrahman et al., 2018; Al-Jaberi and Al-Mayyahi, 2018; Mamaseni, 2020). Core data is of great importance in knowing the petrophysical properties of geological formations with high accuracy and enhancing well log information. 
In the western part of the Zagros basin, the Early Miocene Euphrates Formation is thought to be the main aim of the Tertiary petroleum system. In the Western Deseret of Iraq, it is exposed on surface characterized by open see environment (Al-Dabbas et al., 2013; Al-Dabbas et al., 2014). It is the most important oil reservoir in the Qayyarah oil field, which is characterized by its good permeability and porosity. This study aims to evaluate the petrophysical characteristics of the Euphrates Formation rocks in the Qayyarah oil field by analyzing well $\log$ and core data to predict the ability of this formation to produce oil.

\section{Study Area}

The Qayyarah oilfield is situated on the west bank of the Tigris River in Iraq, in the Qayyarah subdistrict southern Nineveh (50-60 km south of Mosul). According to Iraq's tectonic model, the research area is located within the low-folded zone (Sadeq and Yosiff, 2015) (Fig. 1). It is one of the most significant fields in Nineveh's southern region. The asymmetrical anticline extending southeastnorthwest is the main structure of the Qayyarah oil field with flank dips of about 3 to 6 degrees. The field's length and width are approximately 16 and 4-5 kilometers, respectively.

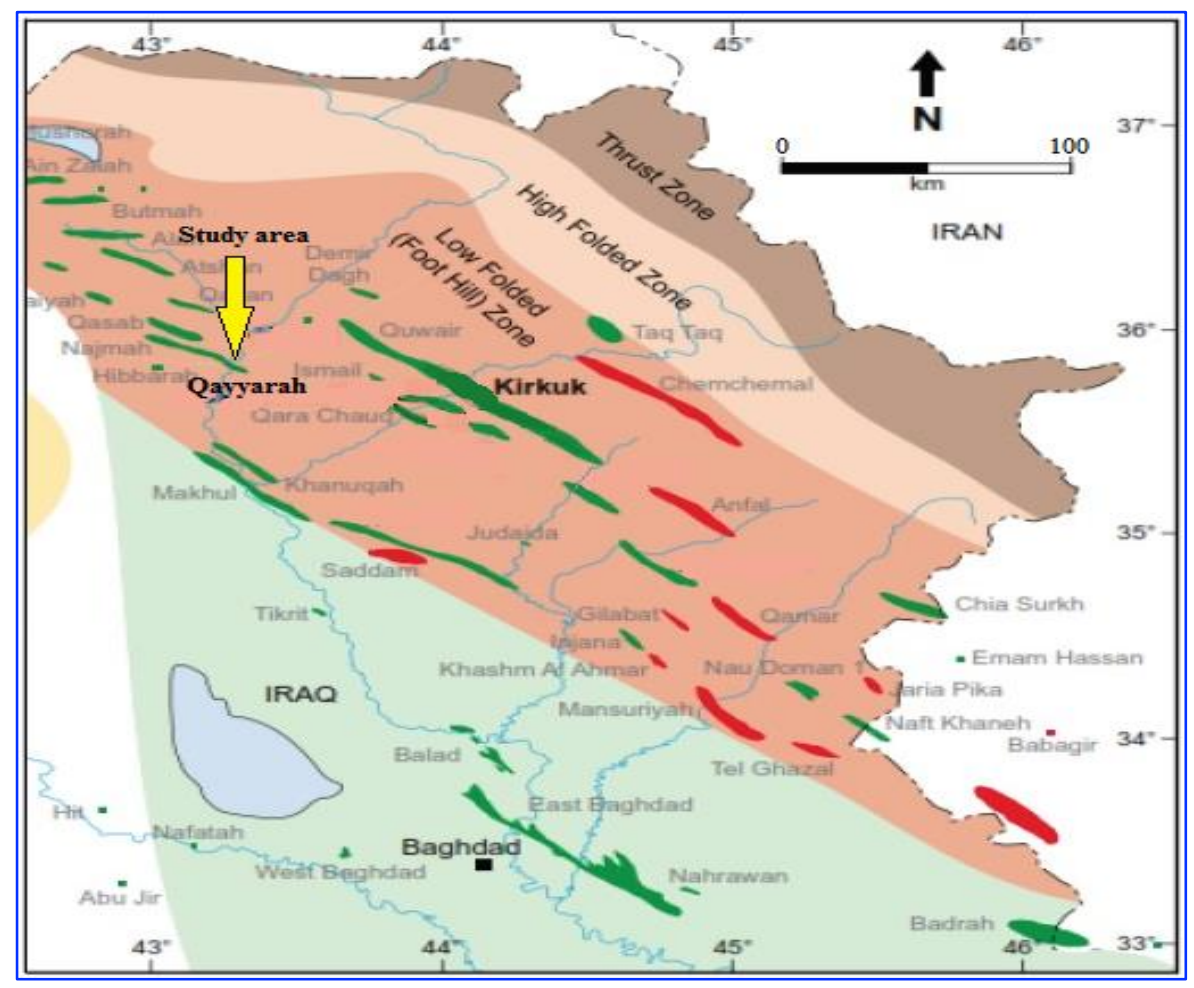

Fig.1. The map of northern Iraq's significant oil fields, with Qayyarah oil field location (modified from Sadeq and Yosiff, 2015).

Stratigraphically, the Euphrates Formation, according to Jassim and Goff (2006), is heterogeneous; the formation consists primarily of limestone with textures ranging from oolitic to chalky limestone, which contains corals and coquina shell; mostly recrystallized and siliceous, green marl beds, argillaceous limestone, brecciated conglomerate, and conglomeratic limestone also present. The Euphrates Formation was divided into two units (Berbakhesh, 1990): the lower unit, which is influenced by dolomitization and recrystallization, and the upper unit, which is not affected by diagenetic processes. 


\section{Materials and Methods}

Two types of data were used in this research; the first was the core data of well Qy-54, and Qy-55 while the second was based on the well log analysis data of the two wells (QY-54, and Qy-55).

\subsection{Core Data}

Core samples were collected from different depths within the wells (Qy-54, and Qy-55) and laboratory experiments were performed on samples to measure several petrophysical parameters. The permeability for core models was measured by placing the model in the Hassler cell and passing the dried air into it with a suitable pressure difference. By using the appropriate pressure throttle, the velocity of the air passage in the model was found and the permeability was calculated. According to Boyle's law, the porosity measuring device depends on the volume measurement of the expanded gas. The sample is placed in a Hassler cell to measure the size of the pores by allowing the nitrogen gas to expand from the gas cylinder inside the sample pores.

By placing large samples saturated with saline solution in a special cell and applying nine successive pressures on them $(0,0.5,1,2,4,8,15,25$, and $35 \mathrm{psi})$, capillary pressure-water saturation curve was found. The percentage of saturation at each pressure is calculated after making necessary corrections such as salinity and particle size lost.

\subsection{Well Log Data}

Since the core samples not include all depths, so the log data information of the two wells (Qy54, and Qy-55) was used to obtain integrated data for all depths within the Euphrates Formation. Different types of logs were used in this study such as caliper, resistivity, and spontaneous potential, gamma-ray, and porosity logs. These well log data are analyzed using the Interactive Petrophysics software (IP version 3.5)

\subsubsection{Porosity}

Porosity refers to the amount of space inside a rock that can be occupied by fluids like oil, gas, and water. Porosity calculation is the second stage in the well $\log$ analysis, and it can only be done correctly if the first step (lithology interpretation) is precise. There are numerous porosity measurement methods available to users using density logs, sonic logs, neutron logs, and all. Neutron-density logs are the most common combination. The formula below was used to calculate porosity (Boddy and Smith, 2009):

$$
\begin{gathered}
\text { NPHID }=\frac{\text { NPHI }+ \text { PHID }}{2} \\
\text { PHID }=\frac{\rho m a-\rho b}{\rho m a-\rho f} \\
\text { PHIS }=\frac{\Delta \text { Tlog }-\Delta \text { Tma }}{\Delta \text { Tf }-\Delta \text { Tma }} \\
\text { PHIsec }=(\text { NPHID }- \text { PHIS })
\end{gathered}
$$

where $\rho$ ma is the matrix density $(2.87 \mathrm{~g} / \mathrm{cc}$ for dolomite), $\rho f$ is the fluid density $(1 \mathrm{~g} / \mathrm{cc}$ for freshwater), $\rho b$ is the density log reading, $\Delta \mathrm{t}_{\mathrm{f}}$ is the transit time of fluid in $\mu \mathrm{sec} / \mathrm{ft}$ (189 $\mu \mathrm{sec} / \mathrm{ft}$ for freshwater), $\Delta$ tlog is the transit time (from sonic log reading) in $\mu \mathrm{sec} / \mathrm{ft}, \Delta \mathrm{t}_{\mathrm{ma}}$ is the transit time of matrix in $\mu \mathrm{sec} / \mathrm{ft}$ ( $43.5 \mu \mathrm{sec} / \mathrm{ft}$ for Dolomite), PHID is the density porosity (derived from density log), NPHI is the neutron porosity (from neutron log reading), PHIS is the primary porosity (derived from the sonic $\log$ ), PHIsec is the secondary porosity, and NPHID is the neutron - density porosity (Boddy and Smith, 2009). 


\subsubsection{Clay Volume}

To determine water saturation, it is necessary to calculate shale volumes, as shale can bind water and increase water saturation. The gamma-ray log can be used for shale volume measurement (Boddy and Smith, 2009). The formula suggested by Larinov (1969), was used for measuring shale volume, as shown below:

$$
\begin{aligned}
& \mathrm{Vsh}=0.33 *\left[2^{(2 * \mathrm{IGR})}-1\right] \\
& \mathrm{IG}=\frac{\mathrm{GR} \log -\mathrm{GRmin}}{\mathrm{GRmax}-\mathrm{GRmin}}
\end{aligned}
$$

where IG is the gamma-ray index, Vsh is the shale volume, $\mathrm{GR}_{\log }$ is the gamma-ray reading, $\mathrm{GR}_{\max }$ is the maximum gamma-ray reading, and $\mathrm{GR}_{\min }$ is the minimum gamma-ray reading. Calculating the volume of shale is an essential step in correcting the porosity values that increase as a result of increasing the proportion of shale volume. This increase is an error in calculated porosity. The correction is usually done using the following equations (Boddy and Smith, 2009):

$$
\begin{aligned}
& \text { PHISc }=\text { PHIS }-(\text { Vsh } \times \text { PHISsh }) \\
& \text { NPHIc }=\text { NPHI }-(\text { Vsh } \times \text { NPHIsh }) \\
& \text { PHIDc }=\text { PHID }-(\text { Vsh } \times \text { PHIDsh }) \\
& \text { PHIE }=\text { NPHID } \times(1-\text { Vsh })
\end{aligned}
$$

where, PHISc, NPHIc, and PHIDc are the corrected different porosity types, PHISsh, NPHIsh, and PHIDsh are the different porosity types of shale, and PHIE is the effective porosity (Ghassem, 2017). The degree of water saturation $(\mathrm{Sw})$ is an important petrophysical property, as it directly contributes to determining the volume of the oil and gas presence in the reservoir (Mamaseni et al., 2018). It can be calculated using the Archi formula as shown below:

$$
\mathrm{Sw}^{\mathrm{n}}=\frac{\mathrm{a} \cdot \mathrm{Rw}}{\mathrm{NPHID}^{\mathrm{m}} \cdot \mathrm{Rt}}
$$

where $a$ is the tortuosity factor ( $a=1$ for carbonate), $m$ is the cementation factor $(m=1.8$ from laboratory measurements), $\mathrm{n}$ is the saturation exponential ( $\mathrm{n}=2$ for carbonate), $\mathrm{Rw}$ is the resistivity of formation water (from Sp log using IP program), and Rt is the true formation resistivity (from resistivity logs using IP program).

\section{Results and Discussion}

\subsection{Lithology Determination}

The lithology of the Euphrates Formation was determined using two types of cross-plots. The first is Neutron porosity (PhiNeu)-Density which is based on the density and neutron porosity logs. Fig. 2 shows the results of PhiNeu-Density cross-plots for the two wells (Qy-54, and Qy-55). The second cross plot used to determine lithology is $\mathrm{M}-\mathrm{N}$ which is based on density, neutron, and sonic logs information. as seen in the following equations (Boddy and Smith, 2009):

$$
M=\left(\frac{\Delta t f-\Delta t \log }{\rho b-\rho f}\right) * 0.01
$$




$$
N=\frac{1-N P H I}{\rho b-\rho f}
$$

The M-N cross plot can be used for determining lithology, detecting gases, classifying clay minerals, etc. (Fig. 3).
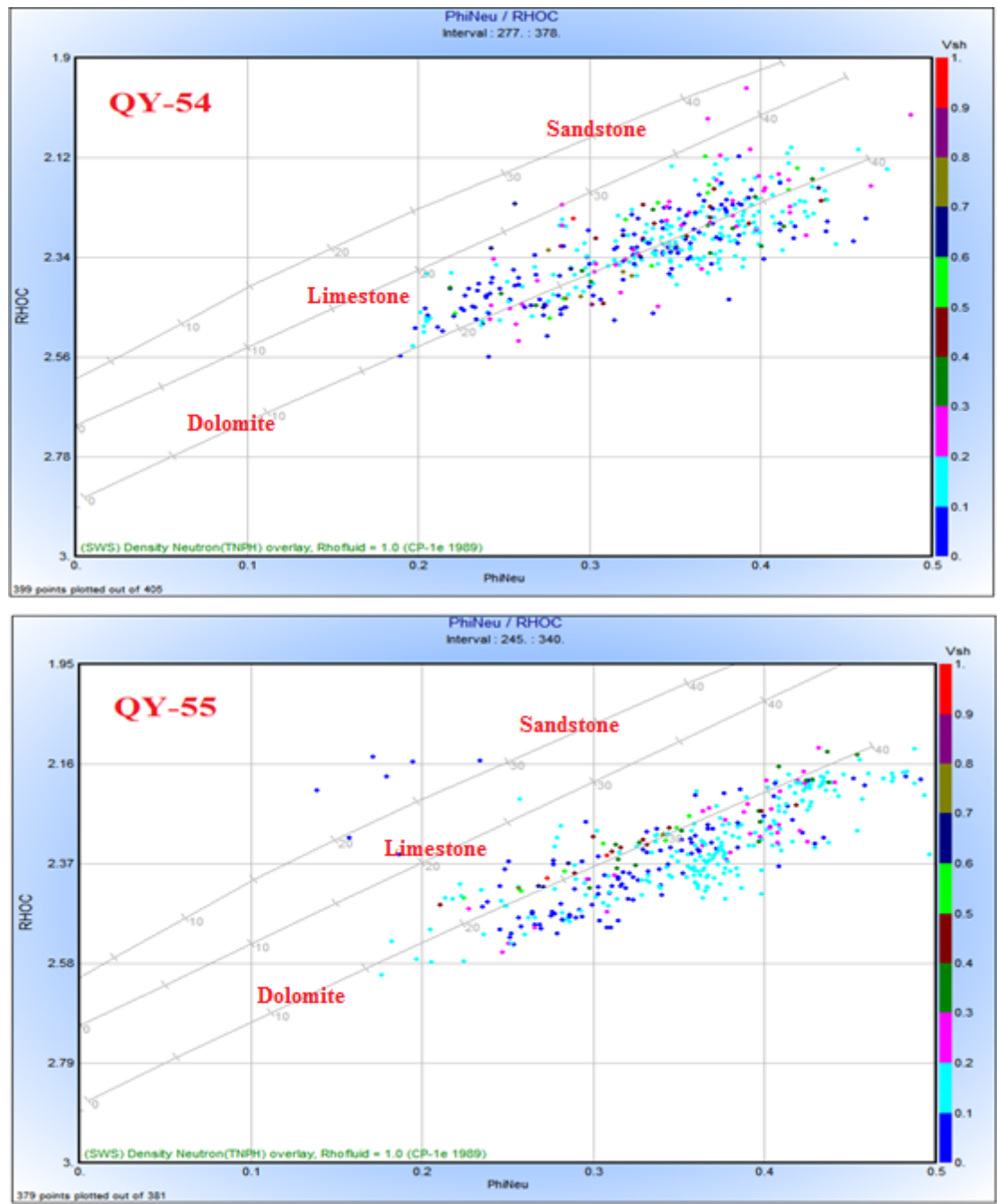

Fig. 2. NPHI-Density cross plots for the two wells (Qy-54, and Qy-55) in the Qayyarah oil field

Both cross plots confirm that the main lithology in both wells is dolomite with small and intermittent amounts of limestone and shale. Shale increases more in well Qy-55, which is evidenced by the deviation of many points to the right of the dolomite curve in the PhiNeu-Density cross plot. Some points in well Qy-54 are deflected towards limestone sites in both Figures, indicating the presence of a small amount of limestone in this well.

\subsection{Porosity Calculation}

The porosity information inferred from well log data of well Qy-55 was compared with the porosity measured from the core data for the same well. It was observed that the density porosity PHID is the most consistent with the porosity information obtained from the core analyses ( $R 2=0.57$ ), while the least compatible one is NPHI (R2=0.45) (Fig. 4). To obtain greater accuracy, PHID in this study, instead of NPHID, was used to calculate the PHIE. 

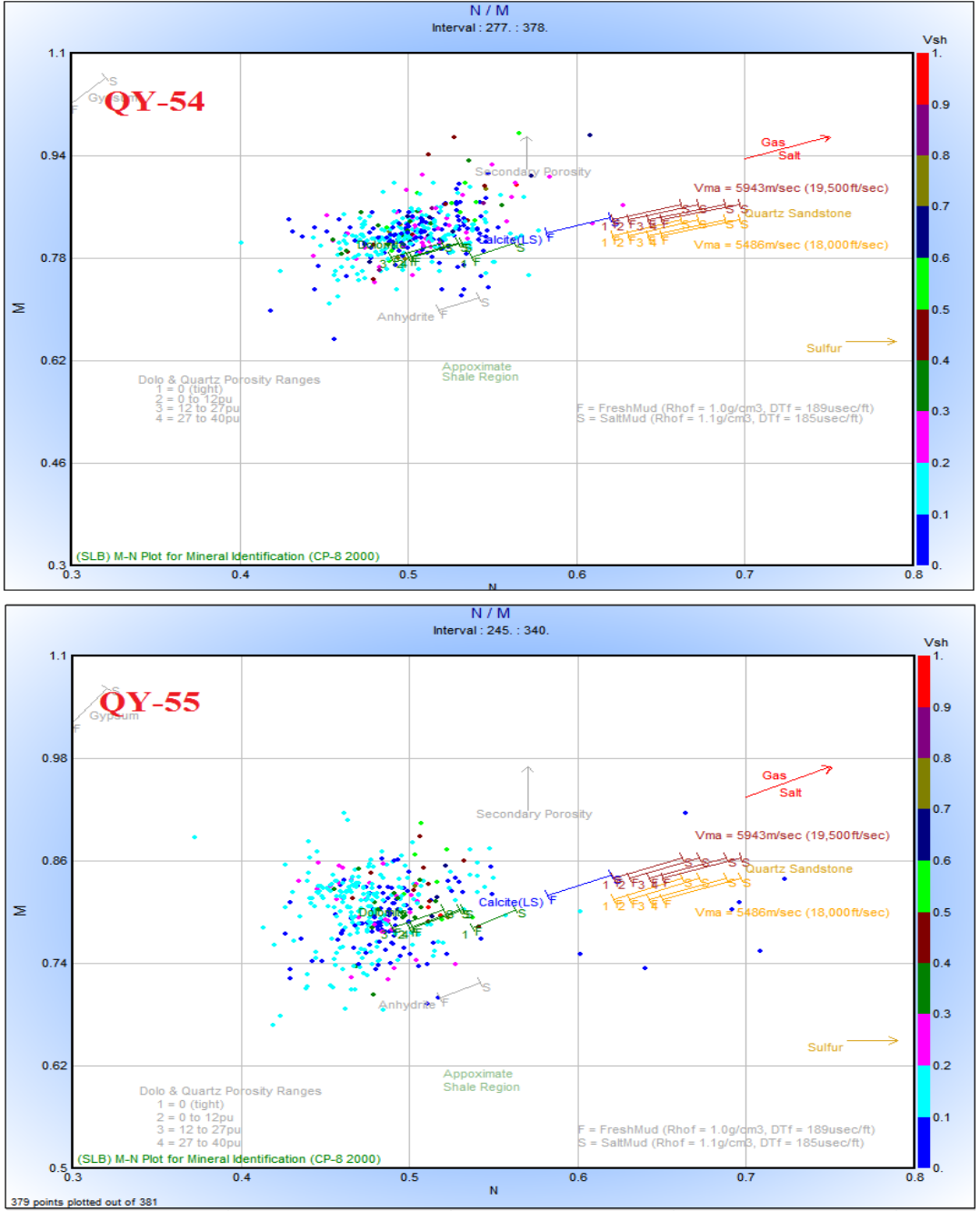

Fig. 3. The M-N cross plots for the two wells (Qy-54, and Qy-55) in the study area
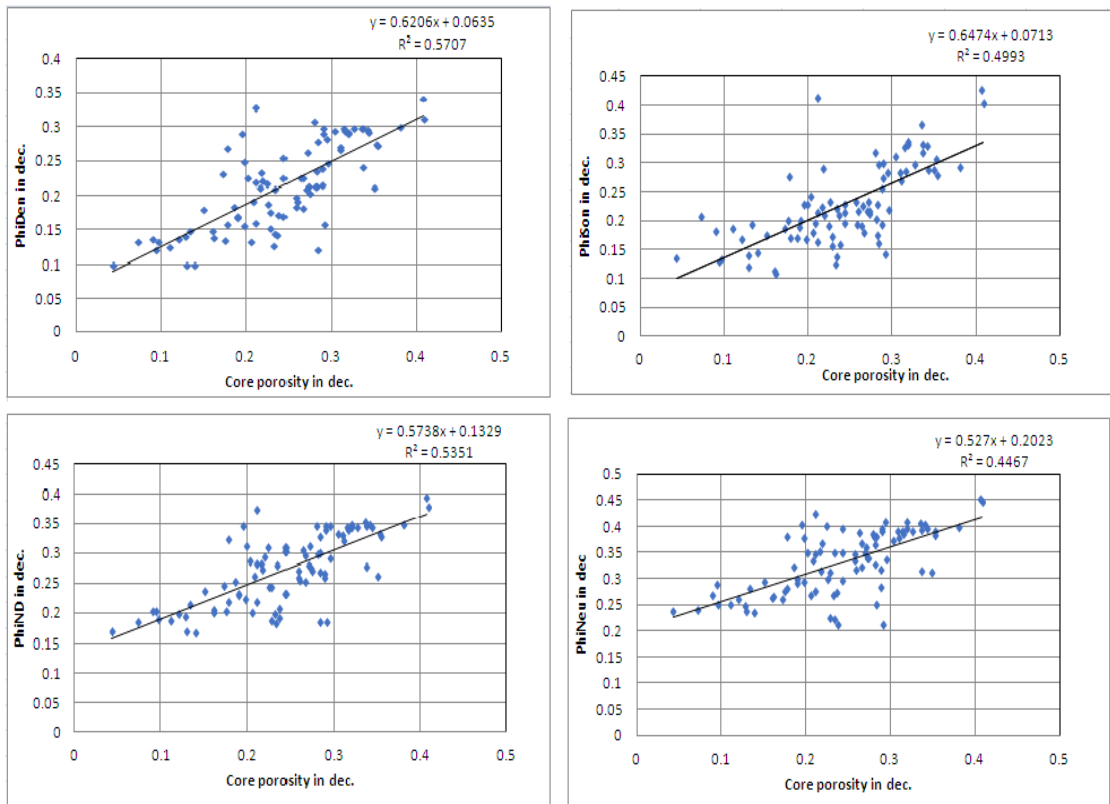

Fig.4. The relationships between core porosity and other porosity types were derived from porosity $\log$ for well Qy-55 in the study area 


\subsection{Core Data Analyses}

After performing the necessary analyzes for some core samples within Euphrates Formation in the two wells, the porosity, permeability, and water saturation information at various depths were obtained to compare it with the well log information of well Qy-55 (Figs. 5 and 6).

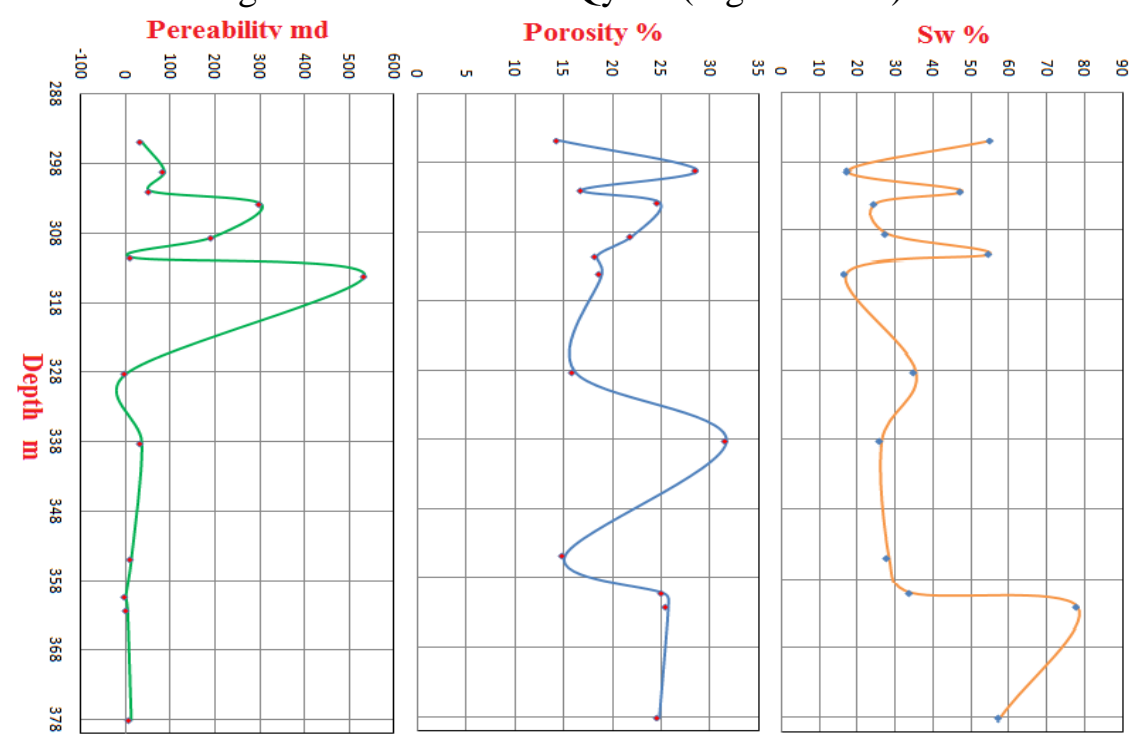

Fig.5. The permeability, porosity, and water saturation curves were produced by analyzing fifteen core samples within Euphrates Formation in well Qy-54.
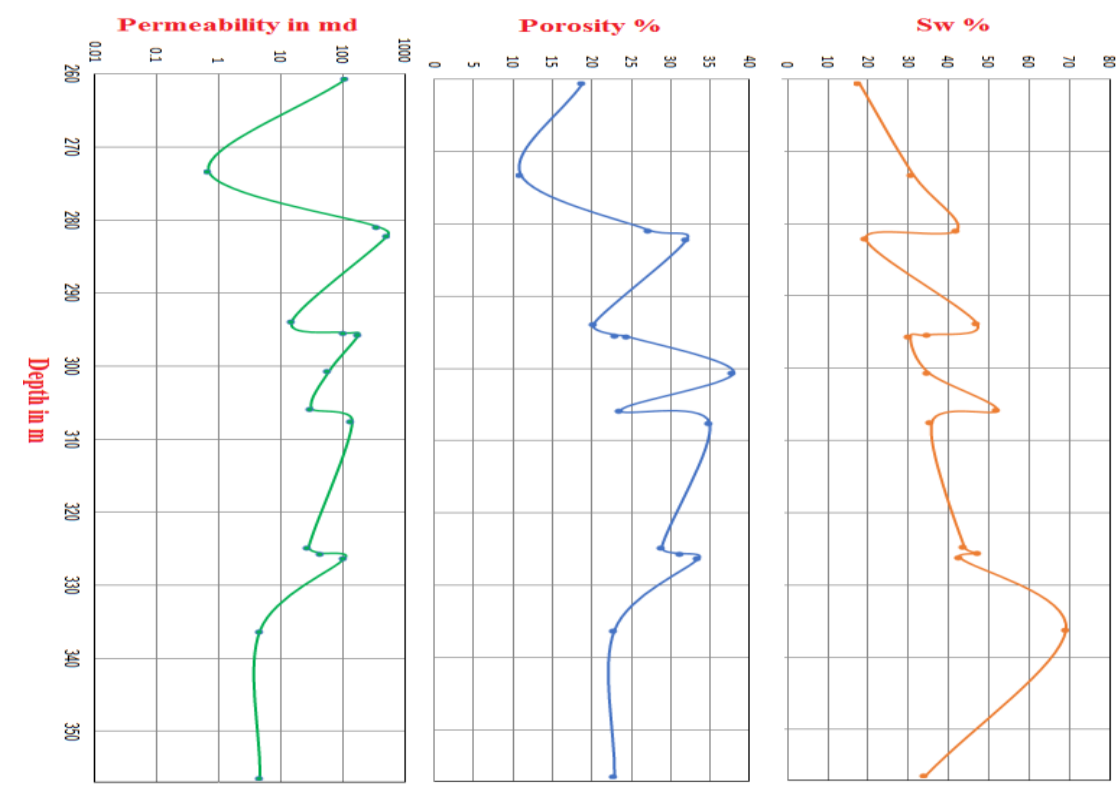

Fig. 6. The permeability, porosity, and water saturation curves were produced by analyzing fifteen core samples within Euphrates Formation in well Qy-55.

From Figs. 5 and 6, it appears that there is a great agreement between the deviations of the three curves, as the increase in porosity corresponding to the increase in permeability and the decrease in water saturation at the most depths. The water saturation $(\mathrm{Sw})$ changes were recorded at different capillary pressures $(\mathrm{Pc})$ for several core samples within the Euphrates Formation at various depths from well Qy-54, and Qy-55. Relationships between Sw and Pc at different depths were plotted (Figs. 7 and $8)$. 


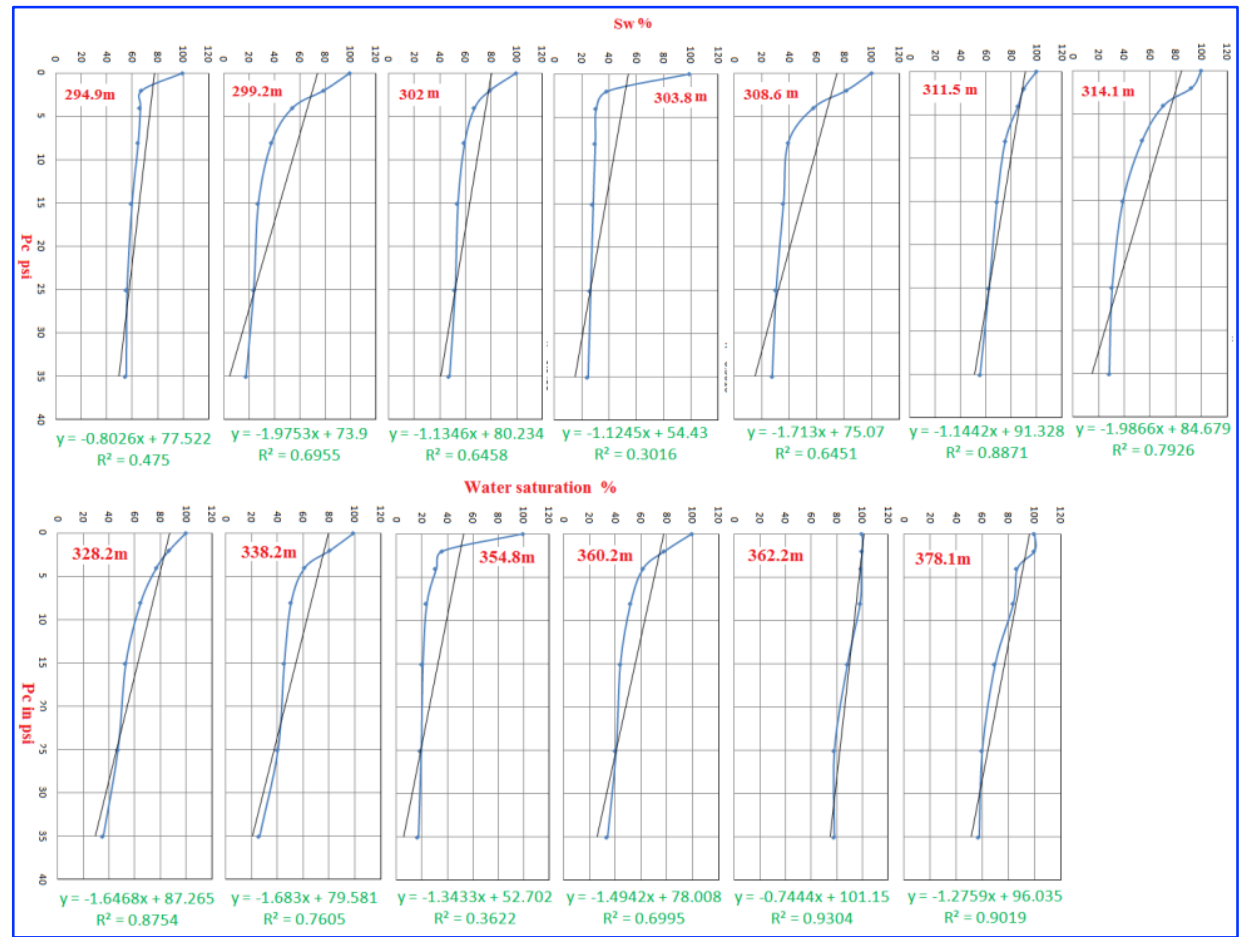

Fig. 7. Sw-Pc relationships for 13 core samples within Euphrates Formation in well Qy-54

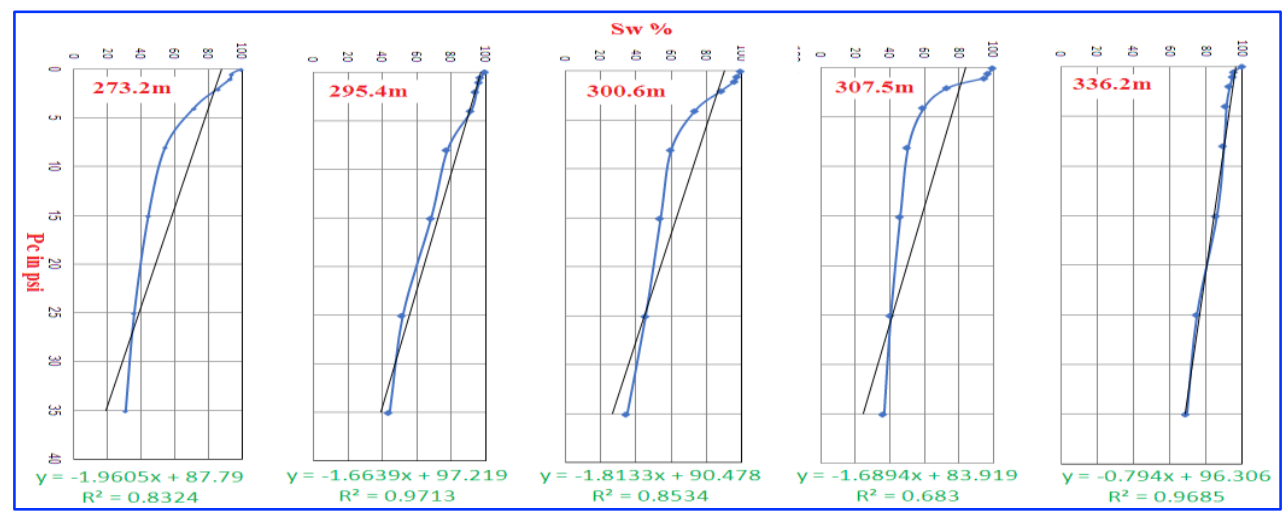

Fig. 8. Sw-Pc relationships for five core samples within Euphrates Formation in well Qy-55

\subsubsection{Well Qy-54}

In Fig. 7, Increasing the coefficient of determination values $\left(\mathrm{R}^{2}=0.89,0.93\right.$, and 0.90$)$ at the depths $(311.5,362.2$, and $378.1 \mathrm{~m})$ respectively may indicate homogeneity in the size of the voids, while decreasing values of $\mathrm{R}^{2}\left(\mathrm{R}^{2}=0.30\right.$, and 0.36$)$ at the depths 303.8 and $354.8 \mathrm{~m}$ respectively indicate the opposite. The large regression of the line in the relationship (Sw-Pc) that appears at depths 299.2, 308.6, and $314.1 \mathrm{~m}$ may refer to the increase in the ratio of large voids to the sum of the total voids in the sample. In most of the examined samples, a significant decrease in Sw occurs when Pc is increased up to $4 \mathrm{psi}$, and then the decrease in Sw becomes gradually after increasing Pc more than $4 \mathrm{psi}$. This may indicate the presence of a proportion of large voids that allow a lot of water to escape quickly at initial pressures $(0-4 \mathrm{psi})$. The large decrease in $\mathrm{Sw}$ at most depths corresponds greatly to the increase in permeability shown in Fig.5. 


\subsubsection{Well $Q y-55$}

A significant increase in the $\mathrm{R}^{2}$ value $\left(\mathrm{R}^{2}=0.97\right)$ at the depth of $295.4 \mathrm{~m}$ was shown in Fig. 8 . which corresponds greatly to the large increase in both permeability and porosity and a sharp decrease in water saturation ( Fig. 6). The large correlation between decreased water saturation and increased capillary pressure (high $\mathrm{R}^{2}$ ) may be a clear indication of normal compaction areas. This may refer to the importance of $\mathrm{R}^{2}$ value to detect the sites of normal compacted zones, which resulted from high shale content or homogeneity in the size of the pores. The last sample $(336.2 \mathrm{~m})$ recorded high $\mathrm{R}^{2}$ values $\left(\mathrm{R}^{2}=0.97\right)$, which corresponds with the porosity and permeability decrease, and the increase of water saturation at their certain depths ( Fig. 6). The variation in the values of $\mathrm{R}^{2}$ at different depths may refer to the variation in the size and shape of the voids. Moreover, the slope of the line resulting from the SwPc relationship is directly affected by the size of the voids. Increasing the negative regression value, since it is an inverse relationship, may be considered a function of increasing the size of the pores. The slope of the line at depth $273.2 \mathrm{~m}$ represents the highest value (-1.96) relative to the five models, which could mean a possibility of a large proportion of large voids at this depth. Besides, the intersection point of the line with the $\mathrm{Y}$-axis (intercept) is an important indicator of the size of the voids. The value of $\left(\mathrm{R}^{2}\right)$ increases when increasing the compatibility between pressure and water saturation (at $273.2 \mathrm{~m}$, and $336.2 \mathrm{~m}$ depths), and this occurs as a result of the similarity in the size of the voids in the sample, which makes it similar in behavior when exposed to a certain pressure. If there is a difference in the size of the voids, the large voids will lose more water and faster when exposed to a certain pressure. The greater the difference, the greater the loss, and this causes a decrease in the value of $\mathrm{R}^{2}$ as the relationship loses part of its compatibility. The large loss of water across large voids increases the line slope of the Sw-Pc relationship, so the slope of the line is a function of the size of the voids. The size of large voids in carbonate rocks may result from fractures and vuggs (secondary porosity), which may indicate the importance of the slope and the value of $\left(\mathrm{R}^{2}\right)$ in knowing the percentage of secondary porosity in the formation, as well as determining the locations of fractures and vuggs.

\subsection{Well Log Data Analyses}

The thicknesses of the Euphrates Formation in the wells Qy-54, and Qy-55 are about 100m, and $94 \mathrm{~m}$ respectively. After making the necessary corrections and calculating the various petrophysical properties, the Euphrates Formation in wells Qy-54, and Qy-55 was divided into three and two zones respectively, depending on the shale volume and porosity changes (Figs. 9 and 10). The oil evidence of the Euphrates Formation appears clearly in the first and second zones (Fig. 9). This appearance corresponds to the increase in porosity, permeability, and true resistivity, which are important indicators of oil presence. In the third zone, the true resistivity values decrease clearly with the increase of both porosity and permeability, indicating a decrease in the proportion of oil in this reservoir accompanied by an increase in water saturation. The secondary porosity shown in the fifth track of Fig. 9 is an indication of the presence of oil as its abnormal negative values may refer to a higher primary porosity than expected. This unusual negativity of the secondary porosity values may be considered important evidence for the presence of oil that appeared in the first and second zones. Due to the presence of a high shale volume in the middle of the Euphrates Formation in well Qy-55, the formation was divided into two zones (Fig. 10). The difference in the Rt curve between the two zones explains the difference between the upper and lower reservoirs. The increasing values of (Rt) in the upper reservoir are associated with the increase in porosity, permeability, and oil saturation, while its values decreasing in the lower reservoir accompanied by an increase in porosity, permeability, and water saturation. most of the parts of the Euphrates Formation in both wells represent reservoir rocks, but the oil saturation ratio varies from one zone to another (Figs. 9 and 10). 


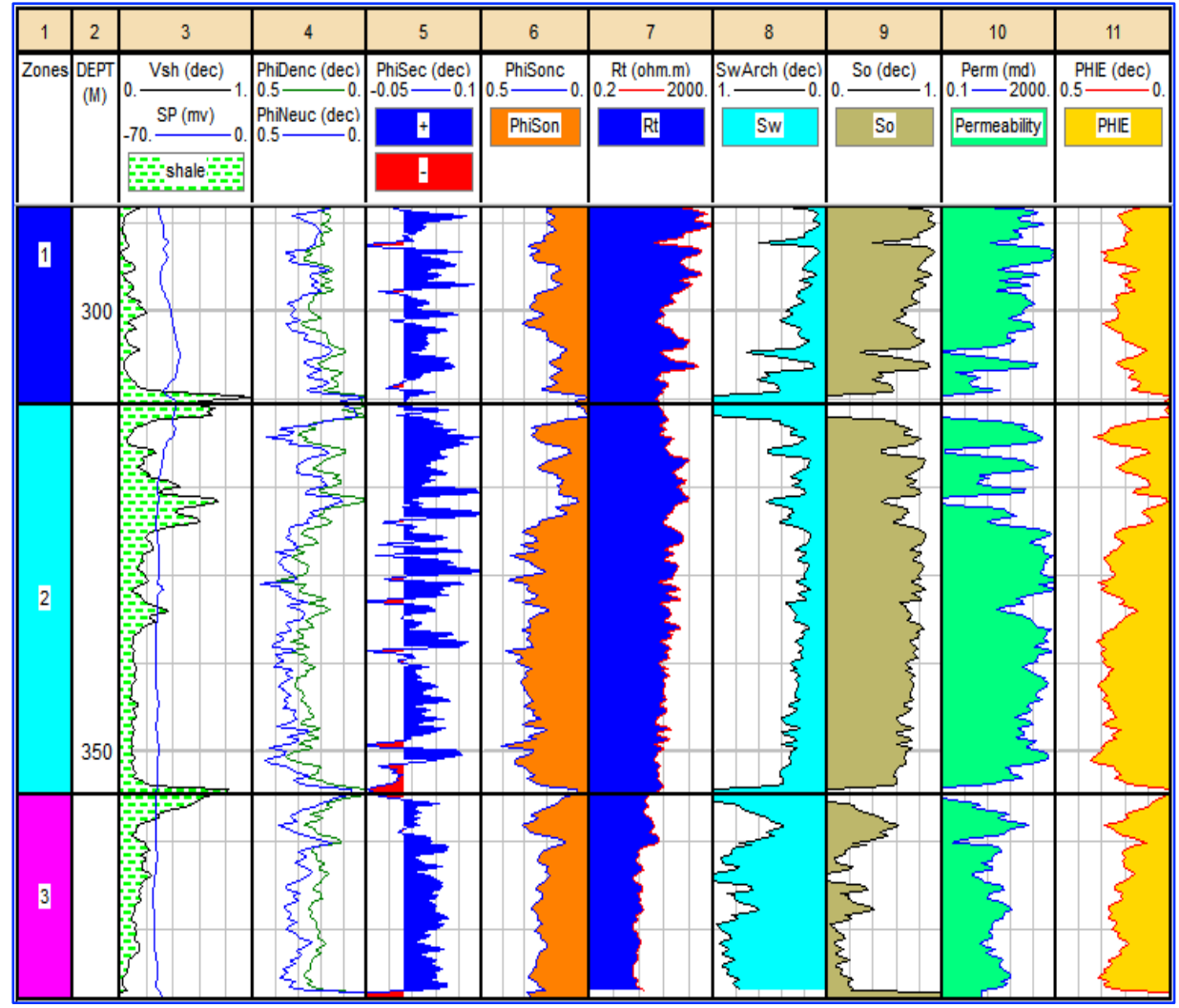

Fig. 9. PCI of Euphrates Formation in well Qy-54

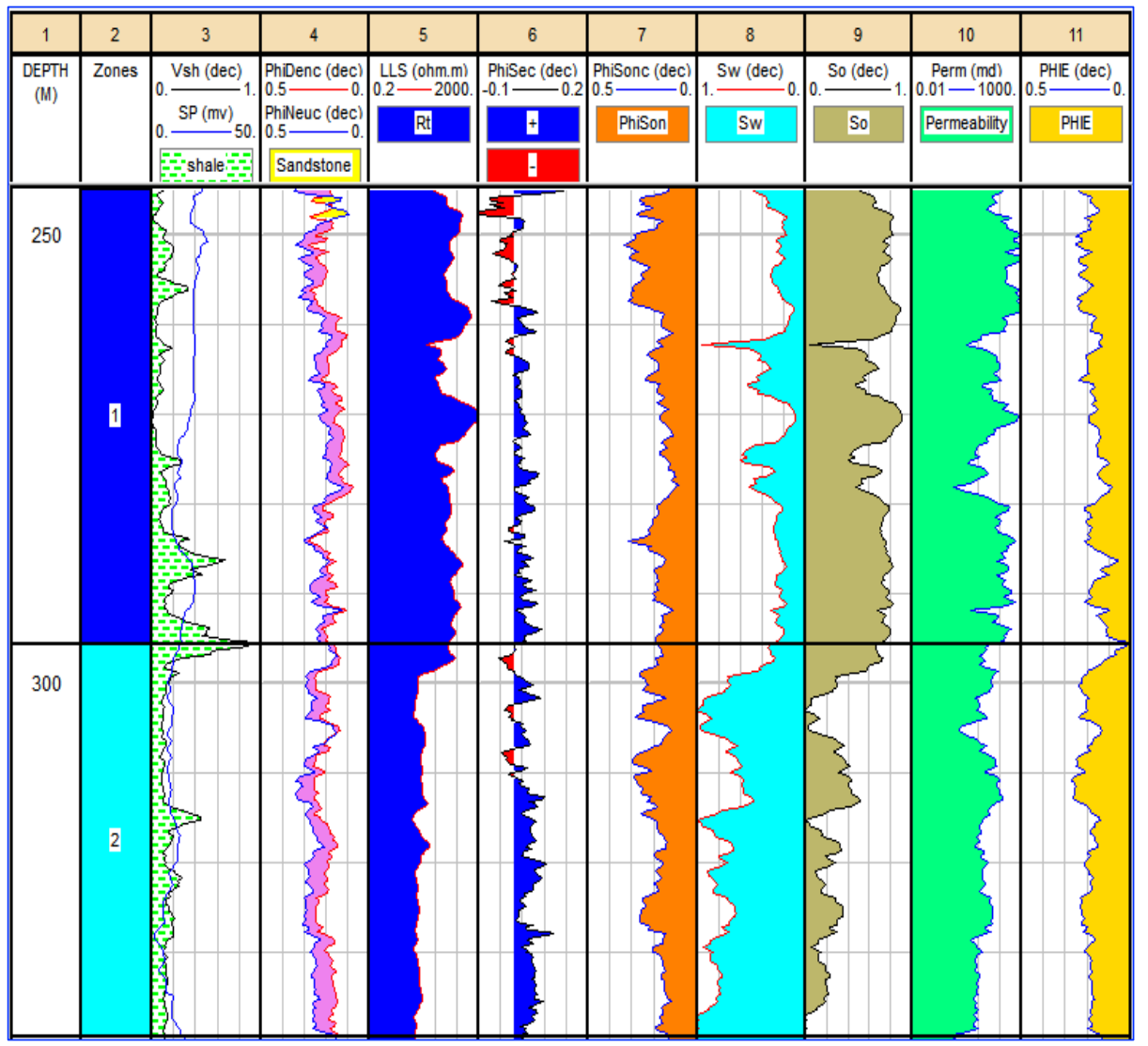

Fig. 10. PCI of Euphrates Formation in well Qy-55 
It is evident from the above that the first and second zones in the well Qy-54 and the first zone in the well Qy-55 represents good oil reservoirs, while the third zone in the well Qy-54 and the second zone in the well Qy-55 are considered water reservoirs because the proportion of oil in them is greatly reduced. After calculating the cutoff values for each of the porosity, water saturation, and shale volume using the IP program, thicknesses and depths of pay zones and gross zones of both wells were found (Figs. 11 and 12). The cutoff values of the Euphrates Formation in both wells, which are calculated using the IP program are: PHIE cutoff $=20 \%$, Sw cutoff $=50 \%$, and Vsh cutoff $=50 \%$, it appears that the thickness of the oil reservoir (red) in well 54 is greater than that of wells 55 . More than $90 \%$ of the formation parts represent reservoir rocks in both wells, but only about $65 \%$ of them are oil reservoirs in the well Qy-54 and nearly 50\% of them are oil reservoirs in the well Qy-55.

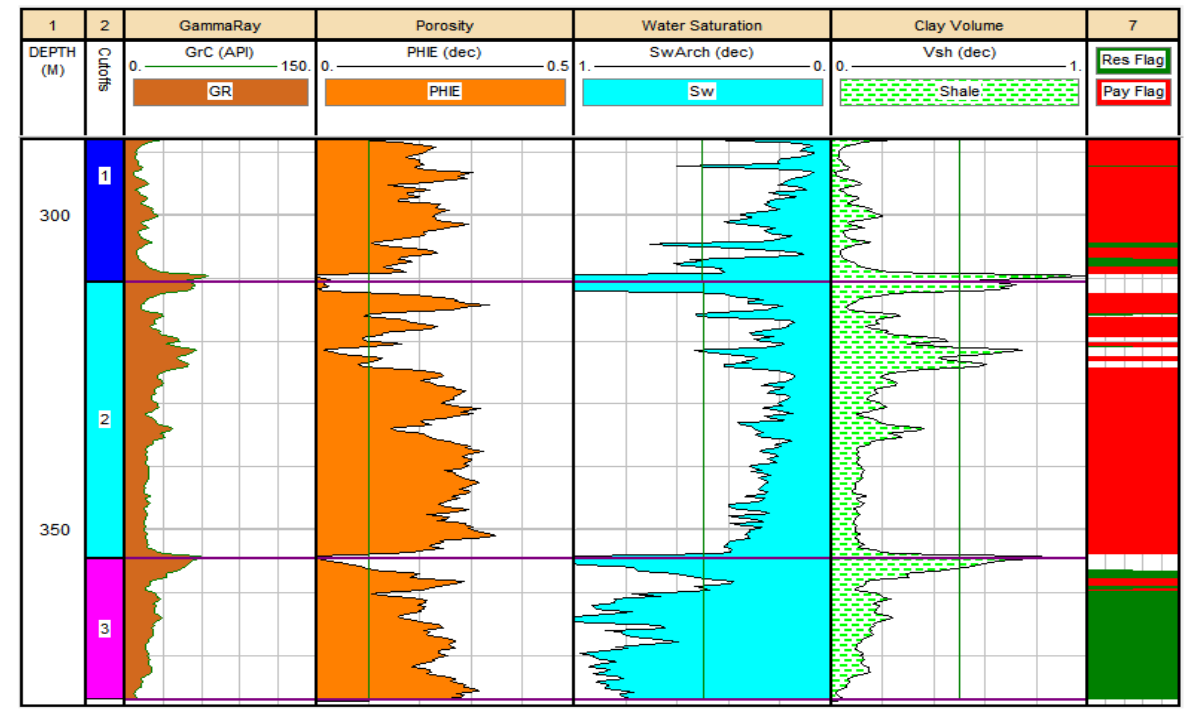

Fig. 11. The cutoff lines (green lines) of PHIE, Sw, and Vsh for Euphrates Formation in the well Qy54. The red and green colors in track 7 represent the pay and non-pay reservoir locations respectively, while the white is non-reservoir sites

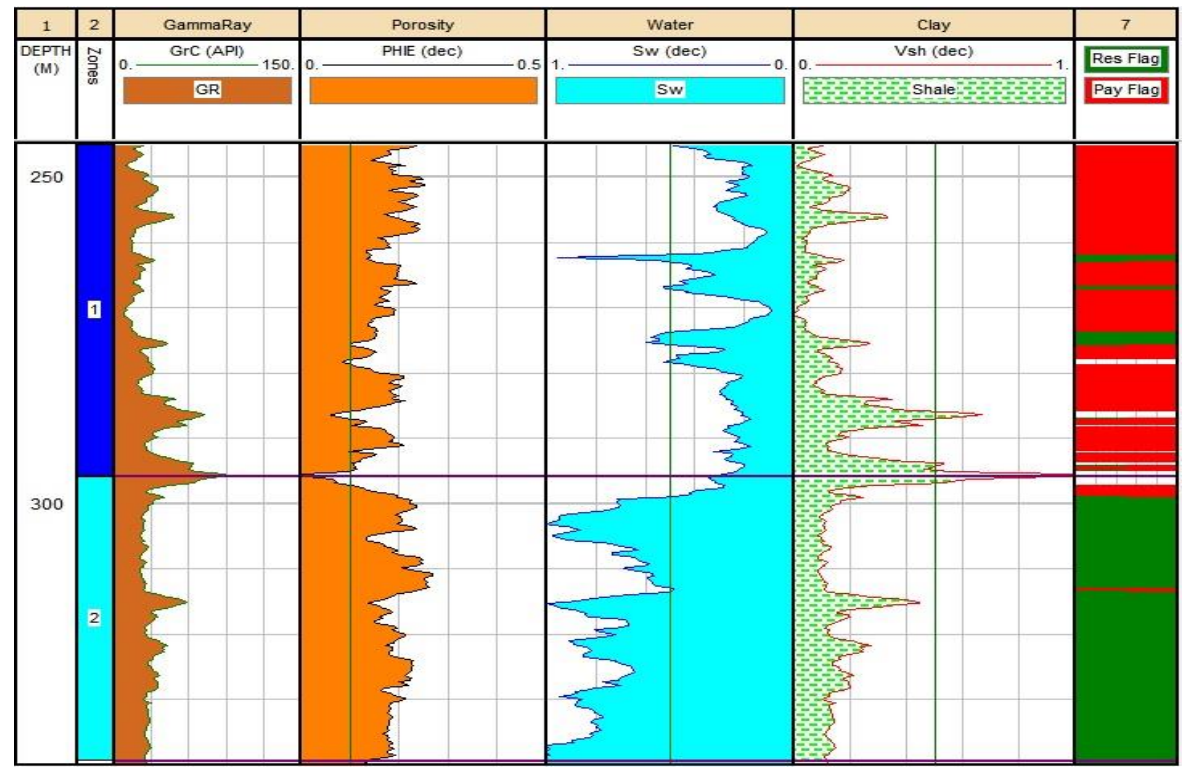

Fig. 12. The cutoff lines (green lines) of PHIE, Sw, and Vsh for Euphrates Formation in the well Qy55. The red and green colors in track 7 are the pay and non-pay reservoirs respectively, while the white is a non-reservoir 


\section{Conclusions}

- The main lithology of the Euphrates Formation produced from various cross plots in this work is dolomite with small amounts of limestone and shale.

- The maximum correlation of core porosity is with the density porosity $\left(\mathrm{R}^{2}=0.57\right)$, so it was used to calculate the effective porosity of the Euphrates Formation.

- The importance of $\mathrm{R}^{2}$ value of capillary pressure- water saturation relationship in determining sites of normal compaction and locations of fractures and vugs.

- Using the line regression for capillary pressure- water saturation relationship as a function of the large void's ratio.

- The validity of negative secondary porosity in predicting the locations of reservoirs in both wells.

- More than $90 \%$ of the formation parts represent reservoir rocks in both wells, but only about $65 \%$ of them are reservoirs in well Qy-54 and nearly 50\% of them are oil reservoirs in the well Qy-55.

\section{Acknowledgements}

The authors would like to thank the Department of Oil Reservoir Engineering, University of Mosul. The author is very grateful to the Editor in Chief Prof. Dr. Salih M. Awadh, the Secretary of Journal, Mr. Samir R. Hijab, and the Technical Editors for their great efforts and valuable comments.

\section{References}

Abdulrahman, S. S., Al-Kubaisi, M. S., Al-Shara'a, G. H., 2018. Formation evaluation for the Jeribe Formation in the Pika gas field, Iraqi Geological Journal, 53(2F), 83-93.

Al-Baldawi, B. A., 2021. Evaluation of petrophysical properties using well logs of the Yammama Formation in Abu Ammod oil field, Southern Iraq, Iraqi Geological Journal 54(1E), 67-77.

Albeyati, F. M. O., Abdula, R.A., Fikret, T., 2021. Porosity and permeability measurements integration of the Upper Cretaceous in Balad Field, Central Iraq, Iraqi Geological Journal, 54(1B), 24-42.

Al-Dabbas, M., Awadh, S.M. and Zaid, A.A., 2013. Mineralogy, geochemistry, and reserve estimation of the Euphrates limestone for Portland cement industry at Al-Najaf area, South Iraq. Arabian Journal of Geosciences, 6(2), pp.491-503.

Al-Dabbas, M.A., Awadh, S.M. and Zaid, A.A., 2014. Facies analysis and geochemistry of the Euphrates Formation in Central Iraq. Arabian Journal of Geosciences, 7(5), 1799-1810.

Al-Jaberi, M. H., Al -Mayyahi, H. K., 2018. Wireline logging response and true core analysis of the upper shale member of Zubair Formation, Rumaila oilfield, Southern Iraq. Iraqi Geological Journal, 51, 28-40.

Al-Jawad, M. S., Kreem, K. A., 2016. Geological model of Khasib Reservoir-Central Area, East Baghdad Field, Iraqi Journal of Chemical and Engineering, 17(3), 1-10.

Al-Majid, M. H., 2019. New petrophysical equations for Hartha-Tannuma interval in the East Baghdad Oil Field, Iraqi National Journal of Earth Science, 2(19), 136-152.

Berbakhesh, A. N., 1990. Microfacies study of Azqand, Anah, and Euphrates formations in Khabaz Field, Northern Iraq. M.Sc. Thesis, College of Science, Salahaldeen University, Erbil, 157pp.

Boddy, R., Samith, G., 2009. Statistical methods in practice, for scientists and technologists, Wiley, U.K.

Ghassem, M. K., Roozmeh, A., 2017. Determination of shale types using well logs. International Journal Petrochem Science and Engineering, 2(5),160-166.

Jassim, S. Z., Goff, J. C., 2006. Geology of Iraq. Dolin, Prague and Moravian Museum, Brno, 341pp.

Larinov, V. V., 1969. Borehole radiometry. Neclra, Moscow.

Mamaseni, W. J., 2020. Petroleum potentiality and petrophysical evaluation of the middle Jurassic Sargelu Formation, Northern Iraq, Iraqi Geological Journal, 53(2D), 77-93.

Mamaseni, W. J., Naqshabandi, S. F., Al-Jaboury, F. K., 2018. Petrophysical properties of the Early Cretaceous Formations in the Shaikhan Oilfield, Northern Iraq, Earth Science, 22(1), 45-52.

Sadeq, Q. M., Yusoff, W. I., 2015. Porosity and permeability analysis from well logs and core in fracture, vuggy and intercrystalline carbonate reservoirs. Journal Aquac Res Development, 6, 371. 